\title{
El fenómeno "pucara" visto desde la Puna jujeña
}

\author{
Marta Ruiz $^{1}$ y María Ester AlbecK ${ }^{2}$
}

De sus pueblos de tierra baja se fueron a poblarse en altos y cerros y peñas...

Guaman Poma (1615)

\section{RESUMEN}

En los Andes Centro Sur el uso del término pucara es ambiguo, dado que se lo utiliza para denominar tanto fortalezas, poblados fortificados, asentamientos naturalmente inexpugnables o sitios estratégicos que controlan recursos o vías de circulación. Cronológicamente comprenden al menos dos momentos, preincaico e incaico. Se relaciona el surgimiento de este tipo de asentamientos con el contexto social y político de los inicios del Intermedio Tardío en los Andes Centro Sur. En la Puna de Jujuy es escasa la presencia de pucara al menos si lo referimos a algunas de las áreas aledañas (Quebrada de Humahuaca). Esto probablemente se pueda referir a particulares condiciones sociales o económicas en el Intermedio Tardio para esta parte de los Andes.

\begin{abstract}
The use of the term pucara is rather ambiguous in the South Central Andes. It is used for naming both fortresses, fortified villages, settlements with a very difficult access, or sites with a strategic location regarding resource control or circulation. Some of these pucara belong to the Inca Period and other are earlier. The emergence of the pucara settlements is related to the political and social conditions in the begginning of the Late Intermediate Period in the South Central Andes. In the Puna de Jujuy the pucara are scarce, at least when we have in mind some nearby areas as the Quebrada de Humahuaca. This can probably be related to particular conditions in this part of the Andes during the Late Intermediate Period.
\end{abstract}

\section{Introducción}

En abril de 1995 se llevó a cabo en el Instituto Interdisciplinario Tilcara, el taller: "Economía y conflicto: Sobre el surgimiento de los llamados pucara en los Andes Meridionales y Centro Sur". En esa oportunidad se realizaron algunos viajes a sitios de la Quebrada de Humahuaca y se visitó el Pucara de Rinconada en la Puna jujeña donde se enfatizó que el único otro pucara conocido para esta zona era el de Sorcuyo, en Casabindo.

El hecho de haber identificado tan solo dos pucara para la Puna jujeña, resultaba sorprendente teniendo en cuenta la abundancia de este tipo de sitios en áreas aledañas (p.e., Quebrada de Humahuaca, Subárea Valliserrana). Si bien este hecho podría deberse a la falta de prospecciones exhaustivas en esta extensa región, es notorio que a más de un siglo de estudios arqueológicos en la Puna, contemos sólo con estas dos referencias a pucara.

El presente trabajo abordará una serie de interrogantes sobre la naturaleza, características, orígenes y dispersión de los pucara. Y se origina en una inquietud que tal hecho nos motivara y que nos impulsó a realizar diversos viajes de estudio a los "pucara" de nuestro país, norte de Chile, altiplano boliviano, sur de Perú y otros más alejados como los de Ecuador.

\section{Pukara: Fortaleza o poblado elevado}

Se admite desde los diccionarios más antiguos consultados (Bertonio 1601; González Holguín 1989 [1608]); que el término pucara ${ }^{3}$ corresponde

\footnotetext{
3 En la introducción del diccionario quechua de Lara, se explica sobre la transcripción de esta lengua. En 1956, en el Congreso Indigenista Latinoamericano, llevado a cabo en La Paz se unificó la escritura advirtiéndose desde ese año que por lo
} 
a fortaleza, fuerte o castillo. Pucara es un término compartido por las lenguas quechua y aymara y como topónimo se registra en gran parte del Area Andina desde Ecuador hasta el centro de Chile.

Al parecer, la dispersión del vocablo está en consonancia con la expansión inca al norte y al sur de Cusco. Aunque el término pudo haberse popularizado con los incas como consecuencia de la construcción de fortalezas, el fenómeno de aparición de asentamientos en lugares altos fácilmente defendibles está asociado a las condiciones sociales de finales del Horizonte Medio y toma auge durante el Intermedio Tardío e Inca.

Ateniéndonos a las definiciones, se podría caracterizar a los pucara como asentamientos de índole netamente defensiva. La bibliografía para los Andes Meridionales y Centro Sur, sin embargo, da cuenta de numerosos sitios que llevan esta denominación y que, a la luz de las descripciones, reflejan un conjunto bastante heterogéneo de asentamientos prehispánicos.

El término pucara aparece indistintamente vinculado a poblados con defensas, sitios naturalmente inexpugnables y fortalezas. En este último caso, algunos autores consignan que se trataría de lugares de "ocupación circunstancial asociados a poblados sin defensas" (Madrazo y Ottonello 1966: 10). Estos mismos autores, desde un punto de vista funcional, consideran a las agrupaciones de viviendas como "poblados agrícolas estables" $\mathrm{y}$, de acuerdo a la concentración de las unidades de vivienda, hablan de "conglomerado"4, "aglutinamiento", "semiconglomerado" y "poblado disperso" (Madrazo y Ottonello 1966: 11-12). Refiriéndose a los conglomerados señalan "que probablemente su misma génesis es la defensiva, manifiesta claramente por la aparición de sistemas

menos seis fonemas se pueden equiparar con nuestra "c". Por esto se tiende a escribir respetando las letras explosivas, aspiradas y sordas. Podemos decir kuntur, k'usi, khipu, q'ara, qasa, qhana.

4 Un conglomerado integra una unidad ecológica con el medio natural del que se provee y constituye también una unidad estructural. Intervinculación entre edificios, proximidad y existencia de vías de tránsito, edificación densa, forma externa definida, que puede darse por murallas, por accidentes topográficos, o muro de circunvalación (Madrazo y Ottonello 1966). de defensas o por la ubicación estratégica (Madrazo y Ottonello 1966: 11).

Si circunscribimos el pucara como una instalación de la época incaica referida a la defensa militar, las ideas más claras al respecto nos llegan de González (1990: 71-72), quien considera las fortalezas entre los asentamientos militares inkaicos. Estas se ubican en sitios fácilmente defendibles en cerros altos y de laderas empinadas, se encuentran en lugares estratégicos, en conjunción de caminos o núcleos de valles. El número de edificios y sus formas son variables y tienen murallas defensivas e ítems arquitectónicos específicos como torreones y troneras (ventanas oblicuas al lienzo de las murallas). Algunos fueron construidos por los incas (Pucara de Aconquija) y otros fueron reutilizados por éstos (Pucara de Rinconada).

Es importante la distinción que hace González entre las fortalezas que se encuentran situadas en el interior del territorio ocupado por los incas y las que se encuentran en los límites o fronteras. Esto es porque su función cambiaba según se buscaba encontrar a los grupos locales dominados y prevenir posibles levantamientos (Pucara de Rinconada) o contener a los pueblos del oriente (Pucara de Andalgalá). Como se sabe los incas no lograron tener un dominio permanente en los valles bajos del este.

Raffino (1988), en cambio, diferencia los pucara con un trazado defensivo pleno y arquitectura militar, equiparando el término con fortaleza o ciudadela (1988: 123), de las instalaciones que carecen de arquitectura militar y sólo tienen como "factor previsor" el terreno donde se asientan. Así, el autor separa a los poblados estratégicos o "pseudopucara", que sólo tienen el factor topográfico como defensa, de los pucara plenos, que sólo podrían considerarse tales en tiempos incaicos, a partir de las conquistas del Inka Topa Yupanqui. Sugiere que el pucara es "el más moderno de los trazados prehispánicos y su presencia estaría destinada a consolidar el espacio incanizado, tanto en sus fronteras como en territorios donde las culturas receptoras no aceptaron el pleno orden inca" (Raffino 1988: 126).

Sin embargo, el uso popular ha llevado a calificar también como pucara muchos sitios que sólo tienen como denominador común un emplazamiento 
estratégico $^{5}$ en el sentido que permiten dominar visualmente un amplio territorio o rutas naturales de acceso (p.e., Pucara de Turi, Chile). Entre este tipo de sitios y las fortalezas propiamente dichas, hay un gran espectro de variantes cuya característica más recurrente es la de ser poblados ubicados en lugares elevados, naturalmente poco accesibles. Hay instalaciones como reducto en sitios altos que a su vez protegen a poblados ubicados al pie, esto es, lo que llamamos asociación poblados-reductos de cumbre (pucara) pero lo más frecuente es que se encuentren los poblados en el mismo reducto de cumbre constituyendo un poblado-pucara.

Ateniéndonos al significado que ha acuñado el uso tendríamos entonces que, latu sensu, pucara corresponde a un asentamiento elevado naturalmente protegido y de acceso dificultoso, con gran visibilidad de su entorno. Este último tipo de instalaciones se populariza en el Intermedio Tardío o Período de Desarrollos Regionales, vale decir, que son preincaicos.

En la mayor parte de los casos se emplazan cercanos a caminos o vías de circulación. Estos también pueden ser preincaicos y señalarían las antiguas vías de intercambio desde Tiwanaku o anteriores y las nuevas redes que se armaron luego del colapso Tiwanaku (indicadas por estos poblados-pucara o poblados-reductos cumbre. También se emplazan sobre las vías troncales o secundarias (qhapaqñan) revalorizadas y extendidas por los incas, en su táctica expansiva. En el caso de algunos pucara que se mencionan como instalaciones militares construidas por los incas, en realidad son también preincaicos. Así sucede con el Pucara de Quitor, en San Pedro de Atacama, cuya construcción comenzó cerca de 1300 DC. El Pucara de Quitor es un ejemplo de poblado con fines defensivos donde cada una de las construcciones, en sí misma, interactúa en un complejo defensivo total (Muñoz 1984).

Si dirigimos la mirada hacia los Andes Meridionales, al menos en la parte que corresponde al territorio

\footnotetext{
5 Decimos lugares altos con sentido topográfico-altitudinal y no lugar estratégico ya que el solo hecho de emplazar un lugar habitacional y/o con otras funciones denota en sí mismo una cualidad estratégica. Del mismo modo los lugares sagrados son simbólicamente estratégicos, por ejemplo el eje acuático del Titicaca, y otros espejos de agua altiplánicos, como las lagunas Chungara y Pozuelos, la ciudad de Cusco, centros ceremoniales de altura, etc.
}

argentino, vemos que el uso del término pucara se ajusta más a su definición más estricta, al utilizárselo para nombrar las fortalezas incaicas como el Pucara de Andalgalá o el Pucara de Aconquija. En otros casos, como en Cortaderas, no se utiliza el término pucara si bien se lo merecería por constituir una fortaleza o guarnición incaica. Los poblados elevados del valle de Santa María y Hualfín como Loma Rica, Eje de Hualfín o Azampay no han sido llamados pucara si bien, por sus características, podrían ser englobados en la categoría poblado-pucara.

\section{El testimonio de los cronistas}

La existencia de pucara o fortalezas fue registrada por los españoles desde sus primeras incursiones por el área andina

“...con este concierto comenzó a subir el gobernador, los caballeros llevaban sus caballos de diestro, hasta que al mediodía llegaron a una fortaleza cercada, que está encima de una sierra en un mal paso, que con poca gente de cristianos se guardaría a una gran hueste, porque era tan agria, que por partes había que subían como por escaleras, y no había otra por do subir sino solo por aquel camino. Esta fortaleza está cercada de piedra, asentada sobre una sierra cercada de peña tajada" (Jerez 1534).

“...repechada la ladera de aquella montaña que se alargó bien media legua, andando por la tarde otro tanto por una cuesta, alcanzó el gobernador otro poblado..." (Pero Sancho 1986 [1534]: 91).

“...por los cerros y collados altos tenían castillos $y$ fortalezas, desde donde, por causas muy livianas, salían darse guerra unos a otros..." (Cieza de León 1547).

Los cronistas dan cuenta del rol del Inka como constructor de estas fortalezas o pucara, pero también hacen referencia a la existencia de pucara en épocas previas al surgimiento del poder incaico. El papel del inca en la construcción de pucara se encuentra reflejado en varios testimonios.

En 1583, el sacerdote Mexia Freire declara que:

“...le mostraron a este testigo mucha cantidad de pucara que son unos cerros que le dijeron que allí se fortificaba el inga en la guerra y para esto los 
mandaba hazer a manera de fortalezas e fosos..." (cit. en Oberem 1969: 203).

Cieza de León por otro lado, registra fortalezas y pucara cuando viajaba por Ecuador; también trae datos de Perú y Chile.

“...entre las provincias de xauxa y caxamaica... mando hacer grandes albarradas y fuertes para defenderse de los naturales..." (1547: 410).

En este párrafo trata del Inka Topa Yupanqui.

“...uso fuertes o cercos [...] que llaman pucaraes..." (1547: 204).

$\mathrm{Al}$ referirse a los incas y a su conquista en el norte de Ecuador dice:

“...quisieron los reyes ingas hacer otra fortaleza, y tenían puestas guardas fieles que tenían cuidado de mirar sus propias gentes no se le volviesen al Cusco o a Quito..." (1547: 260).

Garcilaso de la Vega $(1606 ; 1979)$ también refiriéndose a los incas comenta:

“...mandó hacer muchas fortalezas en las fronteras de lo que estaba por ganar" (1979: 151).

Betanzos en 1561, en cambio, al relatar cómo Topa Inka Yupanki decide castigar un alzamiento en el Collasuyo, refiere:

“... y como los collas se viesen de aquella desbaratados, huyeron y fuéronse a hacer fuertes en el peñol de Pucarane..." (1993: 264).

Más adelante:

“...como allí llegase hallólos que estaban en todos aquellos cerros, y hechas grandes albarradas en ellos, pensando que con aqueollo estaban fortalecidos [...] en breve tiempo los tomaron a desbaratar y echar de los fuertes que allí tenían" (1993: 264).

Este último relato de Betanzos es importante porque confirmaría la existencia de pucara antes de la llegada de los incas al Collasuyo.
En el caso de Guaman Poma de Ayala (1990 [1615]) al referirse al tiempo anterior a los incas, el llamado auqa runa o pachacuti, lo individualiza con un tiempo de conflictos y guerras:

“...de sus pueblos de tierra baja se fueron a poblarse en altos y serros y peñas [...] y comenzaron hacer fortalezas que ellos les llamaban pucara. Edificaron las paredes y cercos y dentro de ellas casas y excondidas y pozos para sacer agua de donde bevían y comensaron a rreñir y batalla y mucha guerra y mortanza con su señor y rrey, brabos capitanes y ballentes y animosos y peleauron [...] y auía mucha suerte [...] y se quitauan a sus mugeres y hijos y sus sementeras y chacaras y asecyas de agua y pastos y fueron muy crueles que se rrobaron sus haziendas rropa, cobre y hasta llcualle las piedras de moler..." (1990 [1615]: 63-64).

En la Figura 1, el mismo Guaman Poma ilustra para la edad de auqa runa, un conflicto armado donde desde un pucara se enfrentan los individuos portando guaracas y lanzas y se protegen con escudos.

En la Relación de Santa Cruz Pachacuti (1993 [1613]: 187) algo anterior a la de Guaman Poma, hace referencia al tiempo purum pacharac captin y dice:

“...passaron muchíssimos años y al cabo, después de haber estado ya poblado abía gran falta de tierras y lugares, y como no habían tierras, cadal día a día abían guerras y discordias que todos en general se ocupavan en hazer fortalezas...".

Más adelante, relatando el recorrido de Tunupa dice:

"Lo uno dizen que en un cerro muy alto llamado cacha pucara estaba o abía un ydolo en figura de muger, a el cual dizen que Tunupa tubo gran odio con el dicho ydolo...".

Para la conquista de Chile, se cuenta con la excelente crónica de Gerónimo de Bibar (cit. en Orellana 1988: 109) de la toma del Pucara de Quitor.

“...todos subieron al fuerte con mucho trabajo por se un cerro agrio y muy alto y sin tener más que una vereda por donde los indios subían y se proveían y la defendían..." 


\section{El surgimiento de los pucara en los Andes}

Trataremos de abordar el problema desde una perspectiva de conjunto desde el espacio mayor del Area Andina, evitando caer en lo que agudamente Lumbreras (1981) señaló como "arqueología semántica y de prestigio", es decir, que usaremos periodificaciones que nos permitan una comparación general para el área.

Hasta la década de los años 80 los Andes Centro Sur o Circuntiticaca estaban incorporados en forma más o menos indistinta al Area de los Andes Centrales o al Area Andina Meridional. A partir de la reunión de Paracas (1979) se determinó como área cultural independiente de acuerdo a la distribución de sus rasgos culturales y la coincidencia de sus procesos de desarrollo históricos. Comprende el extremo sur de Perú, desde Arequipa a Tacna, el Norte Grande chileno, desde Arica a Taltal y la región del Desierto de Atacama, la altiplanicie boliviana y los valles desde Cochabamba a Tarija, en Argentina, la Puna de Jujuy y la Quebrada de Humahuaca.

Sin duda, ha sido la región del lago Titicaca la que a través del tiempo ha unido a este territorio de gran diversidad ambiental. Este espacio plural puede ser entendido desde los conceptos de interacción, complementariedad y de centro-periferia, donde el centro es tal no sólo porque es generador de procesos culturales intensos, sino porque existe en permanente relación con los núcleos periféricos y donde la periferia es tal, que procesos emergentes de ella pueden desestabilizar el centro.

En los Andes Centrales y Centro Sur, el Período Intermedio Tardío refleja dos acontecimientos importantes, la caída de Wari en los valles altos de Ayacucho (800 DC) y la desintegración de Tiwanaku (1000 DC). Este momento de tensión y reacomodamiento en los Andes se denomina también Período de Desarrollos Regionales o Reinos o Señoríos Post-Tiwanaku. A pesar de distintos nombres, todos apuntan a señalar a este nuevo período como de nuevas agrupaciones que tienden, de manera general, a un nuevo patrón de asentamiento, nuevos estilos cerámicos, una vuelta a divinidades locales y el culto a los antepasados, que tendría en las chullpa su rasgo arquitectónico más destacado.
La cuenca del Titicaca y toda la región se fractura en nuevas entidades económicas y políticas, con nuevas redes de intercambio que necesitan desprenderse del tiempo anterior, pero a su vez deben legitimar sus nuevas posiciones. Es el tiempo de auqa runa: "tiempo de soldados", es el tiempo de auqa pacha: "tiempo de guerras", es el tiempo anterior a la aparición de los incas.

Para comprender mejor este nuevo panorama es preciso conocer en profundidad los complejos desarrollos de emergencia de Wari y Tiwanaku. Sobre la primera entidad se plantea desde hace mucho tiempo que fueron precisamente las influencias Tiwanaku las que dieron forma a la misma, ya sea por influencia religiosa (Menzel 1964) o por conquistas militares (Ponce 1981). Más recientemente, se ha sostenido que la aparición de la Cultura Wari y su posterior control del Area Andina Central se realizó en forma independiente (Lumbreras 1974; Benavidez 1984).

La emergencia de Tiwanaku no es menos controvertida. Se advierte, sin embargo, una idea principal respecto al inicio de la cultura Tiwanaku. Fue la combinación de varios mecanismos de interacción: la explotación del hábitat del lago Titicaca, el establecimiento de colonias en la faja costera y la participación en una red de intercambios muy fuerte.

Wari y Tiwanaku comparten, en todo caso, un punto en común, que sería Pukara y el resurgimiento del "dios de los báculos", y que puede ser interpretado como el indicio de la aparición del Estado, tanto en el altiplano como en los valles de Ayacucho (Cook 1994). Los territorios de estos dos Estados andinos compartían un límite que se establecía en Sicuani y Sihuas, en la sierra y en la costa, y parecía incluso formar un territorio neutral. Investigaciones que se están llevando a cabo en estos últimos años seguramente demostraran que pudo existir una frontera formalizada en lo político y una frontera no formalizada en lo económico (Núñez y Dillehay 1979; Browman 1980; Mujica et al. 1983; Berenguer y Dauelsberg 1989; Aldenderfer 1993).

Puede comprenderse ahora por qué la inclinación Wari afectó a Tiwanaku. El quiebre de la densa red de intercambios a larga distancia "tiende en su conjunto a cortar la dirección convergente de los movimientos hacia el eje Tiwanaku..." (Núñez y Dillehay 1979: 95). 
Este proceso de declinación se advierte muy gradualmente en los Andes Centro Sur, apareciendo nuevas formas de integración a partir de 1000 y 1100 DC. Es posible que la fragmentación política y económica haya traído aparejada la pérdida de una circulación coherente de bienes, lo que a su vez ocasionó conflictos entre distintos grupos. Estos cambios se perciben más claramente en aquellos producidos a nivel de los asentamientos; los pobladores buscan construir sus aldeas en forma aglutinada $\mathrm{y}$ en lugares estratégicos y/o lugares fortificados. Este proceso, al plegarse sobre sí mismo, da lugar a la formación de desarrollos locales importantes, como los señalados por Lumbreras (1974) cuando hablaba de los Señoríos y Reinos Post-Tiwanaku, que tienden con el tiempo a conformar alianzas y/o unidades políticas confederadas (Hidalgo 1990).

Estas alianzas les permiten conservar antiguas conexiones del tráfico caravanero redefinidas a corta distancia y responder a las nuevas circunstancias con el afianzamiento de la territorialidad discontinua y la organización social dual (Murra 1990) protegiendo además sus recursos desde lugares fortificados o pucara.

Hyslop (1977) ha investigado este proceso en el área lupaqa donde, luego de la caída de Tiwanaku, se observa una intensificación de la economía pastoril, asentamientos en niveles altitudinales no aptos para el cultivo, desarrollo de poblados amurallados en los cerros y entierros en chullpa (sitio colla de Sillustani y Tanka-Tanka, en el extremo meridional del lago). En territorio pacajes, caranga y en Lípez se sabe de la existencia de estos poblados fortificados y de chullpa (LeCoq 1991). Pucara, chullpa y sepulturas en aleros del llamado Señorío Mallku también han sido señalados por otros autores (Arellano y Berberián 1981).

El aumento de población en este momento puede explicar, además, la intensificación de la agricultura con la extensión de campos de cultivo y sistemas de canales, tanto en el altiplano como en las partes altas de quebradas y valles. Si a esto se le suma el tener que mantener vías de intercambio abiertas, puede interpretarse que los poblados fortificados jugaron un rol importante como puertos de intercambio en estos nuevos circuitos. El arte rupestre ofrece, en toda el área, representaciones de este momento de tensión (figuras de arqueros de Rinconada) y de las caravanas (panel de llamas de Rinconada). Es así que encontramos desde el sur de Perú hasta el Noroeste Argentino una serie de poblados fortificados o pucara.

En Perú, el área que comprende desde Arequipa a Tacna es la zona que tiene más afinidad con el norte chileno, por un lado, y una fuerte vinculación con la cuenca del Titicaca, por otro. Los emplazamientos se encuentran en los valles altos de las quebradas. El valle de Arequipa y el de Colca, por ejemplo, evidencian la existencia de poblados fortificados, asociados a andenerías y sistemas de riego; existen también enterratorios en chullpa (Lumbreras 1974).

En los valles del extremo norte chileno, desde Azapa a Camarones, se reconoce en las quebradas altas que llegan al mar, una serie de asentamientos llamados pucara. ${ }^{6}$ En las quebradas del interior y en los oasis del norte chileno se encuentran pucara desde Tarapacá hasta San Pedro de Atacama. ${ }^{7}$

En Perú, en la zona del Mantaro entre los siglos X y XIV, también se evidencia un aumento de población que trae aparejado la consiguiente presión social, es por ello que existe un porcentaje notable de asentamientos que se instalaron estratégicamente sobre los cerros o en valles altos. Estas aldeas nucleadas tienen, entonces, una preferencia por ubicarse en espacios generalmente defensivos y con gran visibilidad del entorno (Matos 1994). Según este investigador se pueden destacar tres tipos de asentamientos distintos en el Período Intermedio Tardío de la zona que va del Mantaro a Xauxa: 1) En la Puna en los lugares con mayor ventaja para el ganado; 2) En lugares estratégicamente defensivos o ciudadelas "chullparias" (Gutiérrez 1937, cit. en Matos 1994) con organización interna tipo "panal de abejas", también señalado por otros autores (Lavalle 1973; Earls 1981).

6 San Lorenzo y Purisa, en Azapa, Pucara de Copaquilla en el mismo valle, Pucara de Huaihuarani, Ancopachane, Chajpa, Incahullo, Mollegrande y Vila Vila en la quebrada de Vitor, Saxamar y Tangani en la quebrada de Oxa y Pucara Hacienda de Camarones en el valle de Camarones.

7 El Pucara de Qollo en Tarapacá, Pucara de San Pedro y Quitor en San Pedro de Atacama que corresponde a la vertiente occidental circumpuneña; en el río Loa medio se encuentran los pucara de Lasana y Chiu Chiu, dos sitios cercanos que responderían a aldeas aglutinadas con chullpa y en posiciones estratégicas son las vegas de Turi y el sitio de Likan, perteneciente este último al Complejo Toconce-Mallku y del cual se conocen cerca de 20 asentamientos entre el sector septentrional de la Provincia de El Loa y la región de Lípez en Bolivia. 
Un dato interesante es que Matos resalta la maestría en "amarrar" las construcciones sobre los farallones y agudas formaciones rocosas que a manera de balcones miran al fondo de las quebradas y precipicios; 3) Un tercer grupo está representado por grandes aldeas asociadas a viviendas corrales, con espacios destinados a cementerios, en donde se distinguen chullpa circulares en forma de pequeños conos conteniendo entierros individuales. Al momento de la conquista incaica estos grupos del Mantaro exhibían una sólida economía, basada principalmente en el pastoreo con amplias zonas agrícolas, la explotación de sal y minerales, fabricación de cerámica y tejidos y elaboración de comestibles deshidratados.

En el bajo Urubamba, trabajos realizados por Kendall (1980) dan cuenta también de asentamientos residenciales en elevadas posiciones para una mejor visualización, por ejemplo el Pucara de Pantillicla (cercano a Pisaq).

En la cordillera intersalar en Bolivia, Lecoq se refiere a la presencia de sitios que tienden a concentrarse en las partes altas de los cerros y alrededor de fuentes de agua, aprovechando al máximo el espacio disponible (Lecoq 1991, 1996). ${ }^{8}$

Según historias de la zona, algunos de estos sitios están "protegidos" por cerros, por ejemplo el cerro Tunupa o cerro Huancacaya. Algunos autores ven en la forma de las chullpa una evocación de estos cerros protectores, sugiriendo una vinculación simbólica entre los antepasados, los cerros y la protección del lugar (Bouysse Cassagne 1987). ${ }^{9}$

En la región andina de Ecuador se tiene evidencia de fortalezas-pucara al norte del río Guayllamba, en la zona de Cayambe, donde se encuentra un conjunto de 13 fortalezas ${ }^{10}$ donde las etnias locales resistieron por más de una década a la penetración incaica en el área. Algunos autores ven en la existen-

8 Pucara Pella. Pucara Loma Acalaya, Chiquini, Pucara ChicaChica, Pucara Loma Ayque, Luma Pucara Saytoco, Pucara Huayllani, Pucara de Cahuana, Pucara de Castamañas I, II y III, Pucara Puchacaya, Pucara Puchucaya, Choq'o Pucara, entre los más destacados (Lecoq 1991).

9 Para ampliación de estos conceptos ver Bouysse Cassagne y colaboradores (1987).

10 Entre éstas se destaca Quitoloma, Pambamarca, Campana Pucara, Censo Pucara y Achupallas, pertenecientes a las etnias cayambe, caranqui, otavalo y cochasqui (Caillavet 1985). cia de estos pucara los factores que permitieron la resistencia (Moreno 1990). Posteriormente fueron reutilizadas por los incas, quienes asentaron alrededor de las fortalezas a mitimaes cercanos a Cusco como Pucaracamayor (Oberemen 1990). El Pucara de Rumichaca, nombrado por Cieza parece ser una fortaleza inca para controlar tanto a las etnias locales como a las fuerzas de ocupación.

Es así que existe una serie de fortalezas a lo largo del camino desde Caranqui a Quito, tanto por el oeste y por el este del volcán Inbabura. En la zona ecuatorial se encuentra el Pucara de Rumicucho, que a pesar de su poca altura pudo tener un doble carácter, como defensa de Quito y el camino al norte y simbólico por su ubicación en tierras llamadas del centro o la mitad, aludiendo justamente a su posición respecto al sol (Almeida y Chávez 1984).

En la región de Loja al sur, territorio de los grupos paltas, de limitada extensión pero de una posibilidad de acceso a pisos ecológicos diversificados, hizo que su hábitat esporádico fuera también su defensa. La conquista incaica tampoco fue fácil en este territorio y se sabe de la construcción de fortalezas o pucara, como por ejemplo en Calva (Moreno 1990).

\section{Los asentamientos del Intermedio Tardío en la Puna jujeña}

Pasemos ahora a ver cuál es el panorama para el Intermedio Tardío o Desarrollos Regionales en la Puna jujeña. Esta zona comprende el sector norte y occidental de la Provincia de Jujuy y limita con la Quebrada de Humahuaca, otros sectores de Puna de la Provincia de Salta y de los vecinos países de Chile (Atacama) y Bolivia (Lípez y Chichas). El sector jujeño de la Puna es el mejor conocido arqueológicamente en Argentina, aun así existen grandes vacíos de información, básicamente porque hay importantísimos sectores que no han sido prospectados aún.

Para el Intermedio Tardío o Tardío-Desarrollos Regionales se reconocen varios poblados prehispánicos, algunos de grandes dimensiones. Sumados a los grandes sitios, hay muchos sitios menores, poco conocidos. Sin embargo, el cuadro que brinda la Puna jujeña, a partir del patrón de asentamiento de sus asentamientos tardíos y la cerámica asociada, es mucho más heterogéneo que el que brinda la Quebrada de Humahuaca que la flanquea por el 
este en buena parte de su extensión. Los sitios de este momento se englobarían, en principio, en dos grandes entidades: Yavi y Casabindo (Krapovickas 1966), aunque aparece un sitio que por sus características debe separarse claramente de las dos entidades nombradas (Albeck 1996Ms). Tanto Yavi como Casabindo probablemente hayan tenido correspondencia con los grupos étnicos, conocidos a través de las crónicas, que habitaban esta parte de los Andes Centro sur. Así, se homologaría lo Yavi a los grupos chicha que ocupaban el sur del actual territorio boliviano y el extremo norte de Argentina y lo Casabindo, a los casabindo y cochinoca que habitaban los sectores de puna cercanos a los poblados actuales que llevan dichos nombres.

En cuanto al patrón de asentamiento asociado con la cerámica de tipo Yavi, tenemos el sitio Yavi Chico, emplazado sobre una terraza fluvial elevada, con construcciones de planta rectangular con muros de piedra y algunas paredes de adobe. Otro sitio de similares características sería Sansana (Krapovickas 1996). Vinculado al mismo tipo de cerámica tenemos al sitio de Yoscaba, ubicado en la cuenca de Pozuelos, en la parte llana que rodea la laguna. El patrón de asentamiento de este sitio corresponde a montículos, algunos de grandes dimensiones (Balbuena 1989). Habría sitios menores de similares características en otros sectores de la cuenca de Pozuelos. Los sitios identificados por Krapovickas y Cigliano (1964) en el río Grande de San Juan, también incluyen en forma mayoritaria cerámica de tipo Yavi.

En la zona donde prevalece la cerámica de tipo Casabindo se han reconocido varios sitios para el Intermedio Tardío. El más conocido es, sin dudas, el Pucara de Rinconada. Este sitio, descrito más abajo, es un poblado ubicado sobre una meseta escarpada. Comprende habitaciones de piedra de plana rectangular. En las inmediaciones del sitio, contra los paredones rocosos, se registra la presencia de chullpa o entierros en aleros. El sitio Agua Caliente de Rachaite aparentemente fue ocupado desde el Horizonte Medio pero perduró hasta épocas hispánicas (Ottonello 1973; Rolandi 1974; Alfaro y Suetta 1976a). Se trata de un sitio emplazado en una pequeña quebrada afluente del río Doncellas y presenta viviendas de planta rectangular levantadas con muros de piedra. En la zona de Casabindo se han identificado tres sitios de similares características pero de mayores dimensiones: Ojo de Agua, Pueblo Viejo de Potrero y Calaverioj.
Los dos últimos se ubican en la parte baja de dos quebradas, mientras que Ojo de Agua se emplaza sobre un afloramiento rocoso poco elevado. Este sitio es el que mayor afinidad presenta con Agua Caliente de Rachaite si atendemos al material cerámico recuperado (Albeck y Dip, en prensa). Los tres sitios presentan recintos de piedra de planta rectangular y, en todos los casos, aparecen restos de chullpa en las áreas cercanas.

El sitio que no puede asimilarse a ninguno de los descritos hasta ahora para la Puna de Jujuy es Pueblo Viejo de Tucute, conocido también como Sorcuyo (Casanova 1938). Se trata de un sitio de grandes dimensiones, ubicado en una quebrada de difícil acceso, y ocupa sectores muy escarpados y otros con menos pendiente. El patrón de asentamiento es de viviendas de paredes de piedra tallada de planta circular y la cerámica es de muy buena factura, pero no presenta decoración. En las inmediaciones de este poblado también se registra la presencia de chullpa. El sitio de Pueblo Viejo de Tucute incluye un elevado afloramiento rocoso sobre el cual se emplaza un pucara, denominado por Casanova Pucara de Sorcuyo (Casanova 1938). Aún no se ha podido establecer si ambos asentamientos son contemporáneos. Este sitio también será descrito en detalle más adelante.

De lo que acabamos de exponer surge claramente el hecho de que la Puna jujeña no es homogénea en cuanto a su poblamiento en el Intermedio Tardío y que, según los restos cerámicos identificados, probablemente hayan coexistido diferentes grupos que mantuvieron lazos de interacción. Así, es frecuente observar fragmentos correspondientes a piezas Yavi en los sitios de Casabindo. Sin embargo, con el escaso conocimiento que se posee, es difícil plantear la naturaleza de estos vínculos.

\section{Pucara de Rinconada}

Las ruinas arqueológicas del Pucara de Rinconada se encuentran a $15 \mathrm{~km}$ del actual pueblo de Rinconada, cabecera del departamento homónimo. En 1902, Ambrosetti al referirse a fortalezas en posiciones estratégicas informa que existe un croquis del llamado Pucara de Rinconada que fue levantado por el Sr. Gerling (Ambrosetti 1902). La próxima mención del sitio la hace Boman (1908) quien dedica extensas descripciones al lugar, a los hallazgos realizados por él y describe además el 
arte rupestre asociado. Boman también levanta un plano del pucara (Boman 1908, 1992: 627-691). Los trabajos de Suetta desde los años 70 hasta su fallecimiento son recogidos en dos publicaciones (Suetta 1970; Suetta et al. 1979).

El sitio se ubica en las mesetas que se extienden por el suroeste de la llanura de la laguna de Pozuelos que se levantan unos $100 \mathrm{~m}$ sobre el nivel del terreno, identificándose cada una de estas elevaciones con los nombres de Peña Fiera, Cerro de las Pinturas, Pucara Chico, Meseta del Pucara, Meseta de Chacuñayo. Al oeste se levantan las sierras de San José y Cobalonga y al este, luego del reconocible cerro Pan de Azúcar, se puede observar la serranía de Cochinoca.

La meseta en donde se encuentra el Pucara de Rinconada es solamente accesible por el flanco sur, en donde hay una serie de andenes de cultivo "apoyados" sobre grandes bloques de piedra. ${ }^{11}$ El tramo final del ascenso está escalonado y se accede al pucara por una abertura flanqueada por unos muros no muy altos, no defensivos sino de contención, ya que su posición topográfica hace del pucara un lugar estratégico natural.

Puede identificarse como un conglomerado con defensa (Madrazo y Ottonello 1996) o como un poblado-pucara. Allí se encuentran recintos habitacionales, calles, canales y un sector incaico bien identificado, en parte contemporáneo con las otras construcciones. Esta situación nos lleva a pensar que, luego de la ocupación, las relaciones con los incas fueron tolerantes.

De los estudios realizados hasta la fecha, pueden discernirse dos momentos de ocupación, uno en el Período de Desarrollos Regionales y otro con una clara presencia incaica. Se poseen algunos fechados radiocarbónicos que van de 1080 DC a 1490 DC, que deberán ser confirmados en nuevos trabajos, ya que la fecha primera podría estar indicando una ocupación mucho más larga para el sitio.

\footnotetext{
11 Teniendo en cuenta lo destacado por Matos (1994) al hablar del modo en que se "amarraban" las construcciones a las rocas, podemos encontrar ciertas similitudes en los sitios estudiados en la Puna jujeña, sobre todo en lo referente a usar grandes rocas como inicio o sostén de paredes, por ejemplo, de inicio de andenes. En las construcciones de terrazas para nivelar el terreno y utilizarlo para construir las viviendas también puede encontrarse alguna vinculación.
}

Varios son los temas pendientes a resolver, entre ellos, el sistema de canales que cruza los recintos o los bordes, los reservorios de agua encontrados en la meseta y el arte rupestre asociado (Ruiz y Chorolque 1997) que, aunque conocido, no ha sido objeto, hasta ahora, de un estudio que lo relacione con las distintas ocupaciones del pucara.

Los recursos de los alrededores del pucara son importantes tierras para pastoreo y andenes que evidencian actividad agrícola que, si no fundamental, complementaria de otras actividades. También fue vital el recurso faunístico, a juzgar por el significativo consumo de ave evidenciado por los restos óseos y de huevos así como los recursos minerales existentes en la zona. De hecho, algunos autores plantean que la ocupación incaica de la zona pudo estar vinculada fuertemente a la búsqueda de esos minerales. El camino troncal que pasa por Moreta (Matienzo 1566; González 1980) y va hacia Casabindo pasa a cierta distancia del Pucara de Rinconada.

\section{El Pucara de Sorcuyo o Tucute}

Este pucara fue dado a conocer por Casanova (1938) al tratar el sitio de Sorcuyo, el que ha sido redefinido como Pueblo Viejo de Tucute por ser éste el primer nombre que se le dio (Seler 1894, al tratar las colecciones recuperadas por Uhle, cit. en Boman 1908) y que se conserva el día de hoy (Albeck 1996Ms).

En Pucara de Tucute o Sorcuyo se encuentra en la quebrada de Tucute, afluente del río Negro, aproximadamente a $8 \mathrm{~km}$ del poblado moderno de Casabindo. Ocupa un reducido espacio en la cima de un afloramiento rocoso de paredes verticales que, aparentemente, es la misma formación rocosa que la del Pucara de Rinconada. Estos paredones bordean el sitio en todo el contorno. En este caso, sin embargo, el único acceso posible, por el lado sur, es sumamente dificultoso y cuenta con grandes muros defensivos sobre el talud. En la cima del sitio los recintos, con paredes de piedra, son de formas rectangular, circular e irregulares, adaptándose a las formas del cerro (Casanova 1938).

La cerámica corresponde, en forma mayoritaria, a vasijas de grandes dimensiones, pero llama la atención que presenta características de pasta y decoración diferentes a la cerámica recuperada en 
el poblado arqueológico que se encuentra al pie. Sin embargo, como este último sitio es de grandes dimensiones y sólo ha sido estudiado un sector del mismo, es probable que se pueda relacionar la cerámica del Pucara con algún otro sector de ocupación de Pueblo Viejo de Tucute. En este último caso, de ser contemporáneos ambos sitios, estaríamos en presencia de un "reducto de cumbre" con el poblado al pie.

En el caso del Pucara de Tucute, si bien se encuentra en un lugar fácilmente defendible, su emplazamiento respecto al control de recursos o de tráfico parece poco significativo. La quebrada de Tucute no es una vía de circulación de importancia, existen otras en la zona de Casabindo que la conectan de manera mucho más efectiva con los pasos que conducen al oeste. Si bien desde la cima se cuenta con un fantástico dominio visual del Bolsón de MirafloresGuayatayoc y de la serranía de Casabindo, estos sectores se encuentran muy alejados del sitio, desde el cual, por lo accidentado del paisaje, no se pueden controlar las quebradas adyacentes ni el tránsito por el bolsón.

\section{El fenómeno “pucara” en la Puna jujeña}

Como se desprende de lo expuesto, el término pucara tiene una definición acotada, restringiéndose a una construcción de índole militar y correspondería, por esta razón, a la época incaica. Los datos de los cronistas consultados apoyan la génesis incaica para los pucara en toda la zona que dominaron, sin embargo, dejan entrever que, en algunos casos, por ejemplo en el Collasuyo, los poblados altos o fortificados pudieron ser anteriores. En algunos sectores de los Andes Centro Sur el término pucara, en el habla popular (¿o de los arqueólogos?), ha pasado a abarcar un conjunto algo heterogéneo de asentamientos arqueológicos. Así, comprende también muchos poblados ubicados en partes elevadas con acceso difícil o, simplemente, poblados con una ubicación estratégica o de control, la mayoría preincaicos.

Los pucara de la Puna jujeña y las áreas aledañas (San Pedro de Atacama, Quebrada de Humahuaca) se engloban dentro de esta última variante. Es a partir de esto que surge nuestra pregunta inicial. Por qué se conocen tan pocos poblados-pucara para la Puna jujeña, o mejor, por qué el patrón de asentamiento del Intermedio Tardío en dicha Puna tiene tan pocos ejemplos de poblados elevados, comparándola con áreas aledañas como la quebrada de Humahuaca. Como planteáramos al principio, podría radicar en la falta de prospecciones intensivas en la zona. Creemos, sin embargo, que ésta no es la única razón. Mientras que en la Quebrada de Humahuaca prácticamente todos los poblados correspondientes al Intermedio Tardío tienen este tipo de emplazamiento, en la Puna de Jujuy se conocen varios poblados ubicados en partes bajas: Agua Caliente de Rachaite (Ottonello 1973), Pueblo Viejo de Potrero (Albeck et al. 1997Ms), Pueblo Viejo de Tucute (Albeck 1996Ms), Yoscaba (Balbuena, com. pers.), Pozuelos (González 1963) o fácilmente accesibles: Yavi Chico (Krapovickas 1966), Ojo de Agua (Albeck 1994b).

Ahora bien, ¿qué situación estaría indicando esta diferencia en el patrón de asentamiento para un mismo momento en áreas aledañas? ¿Cuál fue la razón por la que en la Puna no existió la misma necesidad de instalarse en lugares estratégicos?

Si volvemos al momento en que surgen estos pucara en los Andes Centro Sur vemos que estarían, al parecer, vinculados íntimamente con el colapso de Tiwanaku y, muy probablemente, con la ruptura de las redes de tráfico caravanero manejadas desde el centro hegemónico. En una zona que conocemos con más detalle, la Quebrada de Humahuaca, los poblados-pucara no se ubican en forma aleatoria. Casi sin excepción, los encontramos en los puntos nodales de las rutas naturales, en la confluencia entre quebradas laterales y la quebrada troncal (Albeck 1993).

Volviendo la mirada a la Puna vemos que el emplazamiento de los sitios no se encuentra, mayormente, en concordancia con rutas o caminos. Si bien en el caso de Rinconada la ubicación es estratégica, al dominar visualmente un amplio espacio, la amplitud de la Puna, con múltiples posibilidades de circulación, restringe considerablemente la posibilidad de control directo del tráfico. En el caso del Pucara de Tucute o Sorcuyo, con una excelente visualización del fondo de la cuenca de Guayatayoc, este control es prácticamente nulo por la distancia a la cual se encuentra emplazado el sitio, amén de lo escarpado de los caminos por las quebradas de acceso al mismo. Un sitio que podrían ejercer algún control directo del tránsito sería Ojo de Agua que, si bien no es pucara, se encuentra en el acceso a las áreas agrícolas y pasturas más ricas de Casabindo. Otro caso podría ser Yavi Chico. 
Creemos que el rol que pudieran tener los poblado-pucara podrían referirse a tres aspectos, que no son excluyentes entre sí. Uno sería la faz defensiva. El colapso de Tiwanaku dio lugar al surgimiento de conflictos entre grupos, adyacentes o distantes, que llevaron a la instalación de los poblados en lugares más seguros contra el ataque de extraños. Esto ha sido descrito claramente por Guaman Poma como el tiempo del auqa runa.

El segundo aspecto sería el control de la circulación de bienes y productos a través del tráfico caravanero. Manejada desde Tiwanaku durante siglos pasó a estar bajo el control de diferentes grupos que buscaban ganar un espacio en la compleja red de tráfico de los Andes Meridionales y Centro Sur.

El tercero y último aspecto es el referido al significado de determinados lugares como hitos visuales a distancia con un fuerte valor simbólico. Este aspecto, si bien es el más difícil de establecer a través de la arqueología, no debe desecharse y lo dejamos planteado como otro factor que pudo determinar la instalación humana en ciertos lugares. Tanto el Pucara de Rinconada como el de Tucute se emplazan sobre formaciones rocosas muy notables y fácilmente distinguibles a la distancia.

Ahora bien, si estos tres serían los factores que podrían incidir en el establecimiento en los pucara en los Andes Centro Sur, ¿por qué son tan poco frecuentes en la Puna jujeña? ¿Es un rasgo común con las demás áreas de la Puna Seca? ¿Implica que los conflictos entre los grupos puneños eran poco importantes o que no había disputas por las rutas caravaneras? Este trabajo es tan solo un puntapié inicial para seguir investigando el tema que, creemos, puede arrojar mucha luz sobre los procesos sociales o económicos de esta parte, la más meridional de los Andes Centro Sur.

\section{REFERENCIAS CITADAS}

ALBECK. M. E., 1993. El ambiente como generador de hipótesis sobre la dinámica sociocultural prehispánica en la Quebrada de Humahuaca. Cuadernos 3.

-1994a. Areas agrícolas y densidad de ocupación en la quebrada de Humahuaca. Avances en Arqueología 2 (2).

_ 1994b. El sitio Ojo de Agua de Casabindo. Actas XI Congreso de Arqueología Argentina. San Rafael. En prensa.

_ 1996Ms. Pueblo Viejo de Tucute: Sorcuyo revisitado.

ALBECK, M. E., S. DIP y M. A. ZABURLIN, 1997Ms. Etnicidad y arquitectura doméstica en Casabindo.

ALDENDERFER, M.,1993. Domestic architecture, ethnicity and complementary, in the South Central Andes. Iowa Press.

ALDUNATE, C. y V. CASTRO, 1981. Las chullpa de Toconce y su relación con el poblamiento altiplánico en el Loa Superior, período Tardío. Ediciones Kultrún, Santiago.

ALFARO, L. y J. M. SUETTA, 1976a. Excavaciones en la cuenca del río Doncellas (Prov. de Jujuy, Argentina). Antiquitas XXII-XXIII

1976b. Nuevos aportes para el asentamiento humano en la Puna de Jujuy. Revisión del Pucara de Rinconada. Antiquitas X.

ALMEIDA E. y J. CHAVEZ, 1984. El Pucara de Rumicucho. Banco Central de Ecuador.
AMBROSETTI, J. B., 1902. Antigüedades calchaquíes. Datos arqueológicos de la Provincia de Jujuy. Anales de la Sociedad Científica Argentina, Buenos Aires.

ARELLANO, J. y E. BERBERIAN, 1981. Mallku, el señorío post-Tiwanaku del altiplano sur de Bolivia. Boletín del Instituto Francés de Estudios Andinos 10.

BALBUENA, J. L., 1989. Investigaciones arqueológicas en Yoscaba. Departamento de Santa Catalina, Provincia de Jujuy. Cuadernos 1.

BERENGUER, J. y P. DAUELSBERG, 1989. El Norte Grande en la órbita de Tiwanaku. Culturas de Chile. Prehistoria. Desde sus orígenes hasta los albores de la Conquista, J. Hidalgo, V. Schiappacasse, H. Niemeyer, C. Aldunate e I. Solimano (Eds.). Editorial Andrés Bello, Santiago.

BENAVIDEZ, 1984. Carácter del Estado Wari. UNSCH, Ayacucho.

BERTONIO, L., 1612. Vocabulario de la Lengua Aymara. CERES, IFEA, MUSEF, La Paz.

BETANZOS, 1992 [1561]. Suma y narración de los ingas. Fondo Rotatorio, Cochabamba.

BOMAN, E., 1992 [1908]. Antigüedades de la región andina de la República Argentina y del Desierto de Atacama. Universidad Nacional de Jujuy, San Salvador de Jujuy. 
BOUYSSE CASSAGNE, T., 1988. Lluvias y cenizas. Dos Pachakuti en la historia. Hisbol, La Paz.

BOUYSSE CASSAGNE, T., O. HARRIS, T. PLATT y V. CERECEDA, 1987. Tres reflexiones sobre el mundo andino. Hisbol, La Paz.

BROWMAN, D., 1980. Tiwanaku expansion and altiplano economic patterns. Estudios Arqueológicos 5.

CAILLAVET, C., 1985. La adaptación de la dominación incaica a las sociedades autóctonas de la frontera septentrional del imperio (territorio otavalo). Revista Andina.

CASANOVA, E., 1938. Investigaciones arqueológicas en Sorcuyo. Puna de Jujuy. Anales del Museo Argentino de Ciencias Naturales XXXIX.

CIEZA DE LEON, P. s/f. La crónica del Perú. Editorial Nueva España, México D. F.

COOK, A., 1994. Wari y Tiwanaku: Entre el estilo y la imagen. Pontificia Universidad Católica del Perú, Fondo Editorial, Lima.

EARLS, J., 1981. Patrones de jurisdicción y organización entre los wankas. En Etnohistoria y antropología andina. Lima.

GARCILASO DE LA VEGA, 1979. Comentarios reales de los Incas. Editorial Peisa, Lima.

GISBERT, T., 1994. El señorío de los carangas y los chullpares del río Lauca. Revista Andina 2.

GONZALEZ, A. R., 1963. Problemas arqueológicos de la Puna argentina. Homenaje a Pedro Bosch Gimpera. México D. F.

_ 1980. Patrones de asentamiento en una provincia marginal del imperio. Relaciones XIV.

GONZALEZ HOLGUIN, D., 1989 [1608]. Vocabulario de la lengua general de todo Perú llamada lengua qquichua o del inca. Universidad Mayor de San Marcos, Lima.

HIDALGO, J., 1990. Los indios de América del Sur meridional a mediados del siglo XVI. En Historia de América Latina. Cambridge Press, Editorial Crítica.

HYSLOP, J., 1977. Chullpas of the lupaca zone of the peruvian high plateau. Journal of Field Archaeology 4.

1992. Qhapaqñan. El sistema vial incásico. Instituto de Estudios Peruanos, Lima.

KENDALL, A., 1980. Informe preliminar de la cerámica y de los restos arquitectónicos preincas en el valle del Urubamba. Baessler Archiv.

KRAPOVICKAS, P., 1966. La Puna argentina. Actas del Congreso Internacional de Americanistas.

KRAPOVICKAS, P. y E., CIGLIANO, 1964. Investigaciones arqueológicas en el valle del río Grande de San Juan (Puna argentina). Anales de Arqueología y Etnología 17-18: 71-118.
LAVALLE, D., 1973. Estructura y organización del hábitat en los Andes centrales durante el Período Intermedio Tardío. Revista del Museo Nacional.

LARA, J., 1991. Diccionario qheshua-castellano, castellanoqheshua. Editorial Los Amigos del Libro, La Paz.

LECOQ, P., 1991. Sel et archeologie on Bolivie, quelques problemes l'occupation préhispanique de la cordillére intersalat. Tesis.

_ 1996Ms. I y II Informes del Proyecto Potosí.

LUMBRERAS, L., 1974. Los reinos post-Tiwanaku. Revista del Museo Nacional XL.

- 1981. Arqueología de la América andina. Ed. Batres, Lima.

MADRAZO, G. y M. OTTONELLO, 1966. Tipos de instalación prehispánica en la región de la Puna y su borde. Monografías 1.

MARTINEZ, J. L., 1995. Papeles distantes, palabras quebradas. Las informaciones sobre Lípez en el siglo XVI. ASUR 4.

MATIENZO, J., 1987 [1566]. Carta a S.M. En Crónicas del Tucumán, Siglo XVI. E. Berberián (Ed.), Comechingonia.

MATOS, R., 1994. Punku, centro administrativo inka de la Puna de Junín. Editorial Horizonte, Lima.

MENZEL, D., 1964. La cultura Huari. Compañía de Seguro, Lima.

MILLONES, L., 1987. Historia y poder en los Andes Centrales. Editorial Alianza.

MORENO, S., 1990. Formaciones tribales y señoríos étnicos. En Historia de Ecuador. Quito.

MUJICA, E., M. RIVERA y T. LYNCH, 1983. Proyecto de estudio de la complementariedad económica de Tiwanaku en los valles occidentales del centro sur andino. Chungara 11.

MUÑOZ, E. Restauración del Pucara de Quitor. Estudios Atacameños 7.

MURRA, J., 1990. Las sociedades andinas antes de 1532. En Historia de América Latina. Cambridge Press, Editorial Crítica.

NUÑEZ, L. y T. DILLEHAY, 1979. Movilidad giratoria, armonía social y desarrollo en los Andes Meridionales: Patrones de tráfico e interacción económica (ensayo). Universidad Católica del Norte, Antofagasta.

OBEREM, U., 1990. La fortaleza de montaña de Quitoloma en la sierra septentrional de Ecuador. Ecuador.

1969. El Período Incaico en el Ecuador. En Historia de Ecuador. Quito.

ORELLANA, M., 1988. La crónica de Gerónimo de Bibar y la conquista de Chile. Editorial Universitaria, Santiago. 
OTTONELLO, M., 1973. Instalación, economía y cambio cultural en el sitio tardío de Agua Caliente de Rachaite. Publicaciones I.

PONCE, C., 1981. Espacio, tiempo y cultura. Academia de Ciencias de Bolivia, La Paz.

POMA DE AYALA, G., 1980 [1615]. Nueva coronica y buen gobierno. Editorial Siglo XXI.

RAFFINO, R., 1981. Los incas del Collasuyo. Editorial Ramos. 1988. Las poblaciones indígenas argentinas. Editorial Tea.

ROLANDI, D.,1974. Un hallazgo de objetos metálicos en el área del río Doncellas, Prov. de Jujuy. Relaciones VIII.

RUIZ, M., 1997. Rinconada: Una mirada nueva al pasado prehispánico jujeño. Secter.

RUIZ, M. y CHOROLQUE, 1997. Arte rupestre de Rinconada. Un repensar desde la región. Congreso Internacional de Arte Rupestre. Cochabamba.

SANTA CRUZ PACHACUTI YAMQUI, J., 1993 [1613]. Relación de antigüedades deste reyno del Piru. Instituto
Francés de Estudios Andinos y Centro Bartolomé de las Casas, Cusco.

SCHIAPPACASSE, V., V. CASTRO y H. NIEMEYER, 1989. Los Desarrollos Regionales en el Norte Grande (1000 a 1400 DC). En Culturas de Chile. Prehistoria. Desde sus orígenes hasta los albores de la Conquista, J. Hidalgo, V. Schiappacasse, H. Niemeyer, C. Aldunate e I. Solimano (Eds.). Editorial Andrés Bello, Santiago.

SUETTA, J. M., 1970. Nuevos aportes para el estudio del asentamiento humano en la Puna de Jujuy. Revisión del Pucara de Rinconada. Antiquitas X.

SUETTA, J. M. y otros, 1979. Excavaciones arqueológicas en el Pucara de Rinconada, Prov. de Jujuy. Actas de las Jornadas del Noroeste Argentino, Universidad Nacional de Salta, Salta.

TARRAGO, M., 1989. Contribuciones al conocimiento arqueológico de las poblaciones de los oasis de San Pedro de Atacama, en relación con otros pueblos puneños, en especial el sector septentrional del valle Calchaquí. Tesis de Doctor en Historia. Universidad Nacional de Rosario, Rosario. 